\title{
PSD-95 Is Associated with the Postsynaptic Density and Not with the Presynaptic Membrane at Forebrain Synapses
}

\author{
Carol A. Hunt, Leslie J. Schenker, and Mary B. Kennedy \\ Division of Biology, California Institute of Technology, Pasadena, California 91125
}

PSD-95, a prominent protein component of the postsynaptic density (PSD) fraction from rat forebrain, has been localized by light microscopy to dendrites of hippocampal neurons (Cho et al., 1992) and to the presynaptic plexus of cerebellar basket cells (Kistner et al., 1993). Here we extend these studies to show that an affinity-purified antibody to PSD-95 labels the dendrites of most neurons in the forebrain and of a subset of neurons in the cerebellum. To confirm that PSD-95 is associated with the PSD at forebrain synapses and to clarify whether it is also associated with the presynaptic membrane, we employed immunogold electron microscopy of forebrain synapto- somes. Gold-labeled antibodies to PSD-95 labeled postsynaptic densities in both intact and lysed forebrain synaptosomes but did not label presynaptic terminals or the presynaptic membrane. The asymmetric distribution of PSD-95 at synapses contrasts with that of its homologs, disks-large and ZO-1, which are arranged symmetrically at septate and tight junctions, respectively.

Key words: NMDA receptors; synaptic transmission; glutamatergic synapses; receptor localization; immunocytochemistry; gold-labeled antibodies
Excitatory synaptic terminals in the adult mammalian CNS are held in place by an asymmetric junctional complex (Gray, 1959; Colonnier, 1968; Landis et al., 1974). At the junction, a dense thickening referred to as the "postsynaptic density" (PSD) is visible in the electron microscope on the cytoplasmic face of the postsynaptic membrane (Palay, 1956). We now know that this structure is a postsynaptic specialization of the submembrane cytoskeleton that is located at sites of close apposition between the presynaptic and postsynaptic membranes (for review, see Kenncdy, 1993).

Subcellular fractions enriched in structures with the appearance and dimensions of PSDs were described several years ago by the research groups of Siekevitz (Cohen et al., 1977) and Cotman (Banker et al., 1974). Although these fractions contain at least 15 major protein components, only 5 of them (tubulin, actin, fodrin, and the $\alpha$ and $\beta$ subunits of type.II $\mathrm{Ca}^{2+} /$ calmodulin-dependent protein kinase) were identified by traditional biochemical or immunochemical methods (Kelly and Cotman, 1978; Carlin et al., 1983; Kennedy et al., 1983; Kelly et al., 1984). We recently identified a new major component of the PSD fraction with the use of protein microsequencing and molecular cloning (Cho et al., 1992). This component, termed PSD-95, migrates as a doublet with an apparent molecular weight of $95 \mathrm{kDa}$ on SDS-PAGE. It is a homolog of two other proteins associated with intercellular junctions, the disks-large (dlg) protein from Drosophila melanogaster (Woods and Bryant, 1991) and ZO-1 (Itoh et al., 1993; Willott et al., 1993). Mutational analysis of the dlg protein indicates that it is a critical component of septate junctions between

\footnotetext{
Received Oct. 10, 1995; revised Nov. 27, 1995; accepted Dec. 1, 1995

This research was supported by National Institutes of Health Grant NS28710 to M.B.K. and by National Institutes of Mental Health Training Grant MHO9810 to C.A.H. We thank Pat Koen for help with electron microscopy and Jim Staub for excellent assistance with the printing of photographs.

Correspondence should be addressed to Mary B. Kennedy, Division of Biology 216-76, California Institute of Technology, Pasadena, CA 91125.

Copyright (C) 1996 Society for Neuroscience $0270-6474 / 96 / 161380-09 \$ 05.00 / 0$
}

developing epithelial cells and plays a role in signal transduction pathways that mediate growth control in the developing larvae (Woods and Bryant, 1991). ZO-1 is a component of mammalian tight junctions (Willott et al., 1993) and of adherens junctions that are associated with the cadherin family of adhesion proteins (Itoh et al., 1993). The homologies among PSD-95, the dlg protein, and ZO-1 suggest previously unsuspected evolutionary relationships among tight junctions, cadherin-based junctions, septate junctions in developing insects, and synaptic junctions in the mature mammalian brain.

For several reasons, the location of PSD-95 in CNS synapses has remained uncertain. The PSD fraction from which PSD-95 was purified is prepared by detergent extraction of synaptosomes (Carlin et al., 1980). Thus, it may contain contaminating proteins that precipitated onto the structure during the detergent extraction and also some presynaptic components that adhere to the junctional complex. Furthermore, septate junctions (NoirotTimothee and Noirot, 1980), tight junctions (Citi, 1993), and other cadherin-associated intercellular junctions seem to be symmetric, containing similar components on both sides. In developing embryos and larvae, the dlg protein also seems to be lacated symmetrically because it is visible on both sides of septate junctions (Woods and Bryant, 1991). Similarly, ZO-1 is located symmetrically when visualized by fluorescence and immunoelectron microscopy (Willott et al., 1992; Itoh et al., 1993). In contrast, our initial immunocytochemical investigations in rat hippocampus revealed that fluorescent staining with anti-PSD-95 antibodies is more intense in neuronal dendrites than in presynaptic terminals (Cho et al., 1992). On the other hand, Kistner et al. (1993), using immunoperoxidase staining at the light and electron microscopy (EM) levels, found that PSD-95 (which they refer to as SAP-90) is located in the presynaptic terminal of basket cells in the rat cerebellum and is not expressed in Purkinje cells, which are postsynaptic to the basket cell terminals. Previously, we also have observed staining of the cerebellar basket cell presynaptic terminals in the light microscope with immunoperoxidase-labeled an- 


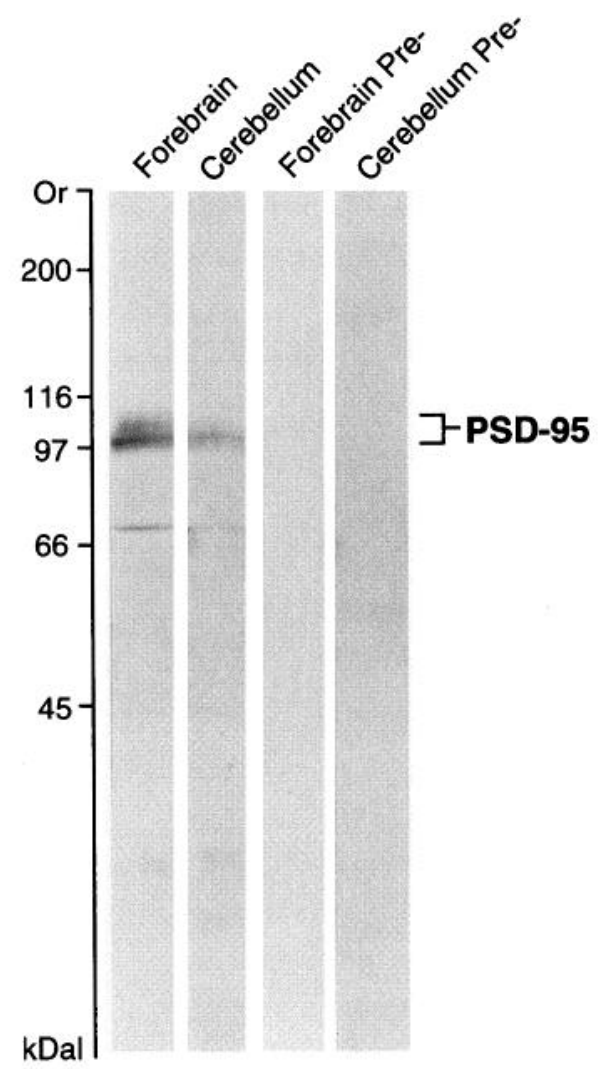

Figure 1. Specificity of anti-PSD-95 antibodies. Rat brain proteins (100 $\mu \mathrm{g}$ ) were fractionated by SDS-PAGE ( $8 \%$ acrylamide) and transferred to nitrocellulose. Strips of nitrocellulose containing the proteins were incubated with $0.4 \mu \mathrm{g}$ of affinity-purified anti-PSD-95 antiserum (Cho et al., 1992) or with $0.4 \mu \mathrm{g}$ of affinity-purified antiserum that had been preabsorbed with $1 \mu \mathrm{g}$ of recombinant PSD-95, as described in Materials and Methods. The position of the PSD-95 doublet is bracketed. Positions of molecular weight standards are at left.

tibodies (Hunt et al., 1992). Kistner et al. (1993) generalized their finding to suggest that PSD-95 is a presynaptic protein in all synapses where it occurs. These latter results called into question the asymmetric concentration of PSD-95 in the PSD in vivo and suggested that its distribution might be symmetric like that of its homologs at other junctions.

We reported recently that PSD-95 associates with the C termini of the subunits of the NMDA-type glutamate receptor via a specific interaction between the second PDZ domain in PSD-95 and the terminal tSXV domain in the receptors (Kornau et al., 1995). This association strongly supports a postsynaptic location for PSD-95. We also reported, however, that several other receptors and families of potassium channels are equipped with a tSXV domain, suggesting that PSD-95 or similar proteins might bind to the cytosolic termini of several classes of membrane proteins in nerve cells. Furthermore, Kim et al. (1995) found that the potassium channel subunit Kv1.4 binds to PSD-95 and related proteins. Thus, PSD-95 could be present at the active zone membrane of presynaptic terminals in association with an as yet unknown protein, as well as associated with NMDA receptors at the postsynaptic membrane.

To test with greater resolution whether PSD-95 is present in PSDs and, if so, whether it is restricted to a postsynaptic role at forebrain synapses or might also function at the presynaptic membrane, we used immunogold EM to examine the location of PSD-95 in synaptosomes prepared from adult rat forebrain. We found prominent labeling of PSDs in both intact and lysed synaptosomal fractions but detected no labeling of presynaptic membranes. Thus, in the forebrain the tight association of PSD-95 with the synaptic junction seems to occur principally on the postsynaptic side at the site of the PSD.

\section{MATERIALS AND METHODS}

Reagents. 3,3'-Diaminobenzidine tetrahydrochloride (DAB) was purchased from Sigma (St. Louis, MO); leupeptin was from Boehringer Mannheim (Indianapolis, IN); low melting point "C Agarose" was from Pharmacia (Alameda, CA); glutaraldehyde and osmium tctroxide were from Polysciences (Warrington, PA); Spurr's embedding medium and paraformaldehyde were from Electron Microscopy Sciences (Ft. Washington, PA); Nonidet P-40, Triton X-100, and Tween-20 were from Pierce (Rockford, IL); acrylamide, SDS, and Affigel-15 were from Bio-Rad (Richmond, CA); and the RIBI adjuvant system (MPL + TDM + CWS) was purchased from RIBImmunochemical Research (Hamilton, MT). Colloidal gold $(10 \mathrm{~nm})$-conjugated goat anti-rabbit $\mathrm{IgG}$ was purchased from Amersham (Arlington Heights, IL). Peroxidase-conjugated eggwhite avidin was purchased from Jackson Immunoresearch (West Grove, PA); biotin-conjugated goat anti-rabbit and horse anti-mouse IgG were from Picrce; and horseradish peroxidase (HRP)-conjugated goat antimouse IgG was from Cappel (Durham, NC). Anti-synapsin I (De Camilli et al., 1983a) and anti-PSD-95 (Cho et al., 1992) antibodies were prepared as described previously. Sprague-Dawley rats were purchased from Simonsen Laboratories (Gilroy, CA); New Zealand White rabbits were from Irish Farms (Norco, CA).

Light microscopy. Sprague-Dawley rats (120-150 gm; 6-8 weeks old) were perfused transcardially under Nembutal anesthesia, briefly with PBS $\left(0.9 \% \mathrm{NaCl}, 0.1 \mathrm{M} \mathrm{NaPO}_{4}, \mathrm{pH} 7.4\right)$, and then for $20 \mathrm{~min}$ with 21 of $4 \%$ paraformaldehyde, $0.2 \%$ glutaraldehyde, and $0.1 \mathrm{M} \mathrm{NaPO}, \mathrm{pH} 7.4$. The heads were cooled for $30 \mathrm{~min}$ on ice, and then the brains were removed and post-fixed overnight at $4^{\circ} \mathrm{C}$ in the same fixative. Brains were sectioned at $15-30 \mu \mathrm{m}$ on a DSK Vibratome into glycine buffer $\left(0.1 \mathrm{M}\right.$ glycine, $\left.0.45 \mathrm{M} \mathrm{NaCl}, 20 \mathrm{mM} \mathrm{NaPO}_{4}, \mathrm{pH} 7.4\right)$. Individual sections were processed essentially as described previously (De Camilli et al., 1983a); they were permeabilized with $0.7 \%$ Triton X-100, treated with glycine buffer followed by $1 \%$ sodium borohydride, and then preincubated in Triton buffer $\left(0.45 \mathrm{M} \mathrm{NaCl}, 20 \mathrm{~mm} \mathrm{NaPO}_{4}, \mathrm{pH} 7.4,5 \%\right.$ normal goat serum, and $0.05 \%$ Triton $\mathrm{X}-100$ ). Sections were incubated overnight at $4^{\circ} \mathrm{C}$ in $0.5-12 \mu \mathrm{g} / \mathrm{ml}$ anti-PSD-95 (Affigel-purified rabbit polyclonal antibodies) (Cho et al., 1992) in Triton buffer. Control sections were incubated in equivalent dilutions of nonimmune rabbit IgG, preimmune serum, or affinity-purified serum preabsorbed with recombinant PSD-95 (Cho et al., 1992). After the overnight incubation, sections were washed three times for $15 \mathrm{~min}$ each in Triton buffer and then incubated for $1 \mathrm{hr}$ at room temperature in HRP-conjugated goat anti-rabbit IgG (Pierce), diluted 1:100 in Triton buffer. Sections were washed again three times for $20 \mathrm{~min}$ each in wash buffer. Peroxidase reaction product was formed by incubating in $0.25 \% \mathrm{DAB}$ in $0.1 \mathrm{M}$ $\mathrm{NaPO}_{4}, \mathrm{pH} \mathrm{7.4}$, and $0.003 \% \mathrm{H}_{2} \mathrm{O}_{2}$ for $7-10 \mathrm{~min}$. In some sections, reaction product was intensified by addition of $\mathrm{NiNH}_{4} \mathrm{SO}_{4}$ and $\mathrm{CoCl}_{2}$, as described by Adams (1981).

Immunoelectron microscopy. Synaptosomes were prepared from forebrains of 6- to 8-week-old Sprague-Dawley rats as described previously (Kennedy et al., 1990). Briefly, four forebrains were homogenized in 16 $\mathrm{ml}$ of homogenization buffer $(0.32 \mathrm{M}$ sucrose, $1 \mathrm{~mm} \mathrm{NaHCO}, 1 \mathrm{~mm}$ $\mathrm{MgCl}_{2}, 0.5 \mathrm{mM} \mathrm{CaCl}_{2}, 0.1 \mathrm{~mm}$ phenylmethylsulfonyl fluoride, and $1 \mathrm{mg} / \mathrm{ml}$ leupeptin). The P2 pellet was isolated by differential centrifugation. A fraction enriched in synaptosomes was prepared by discontinuous sucrose density gradient centrifugation (Carlin et al., 1980). The synaptosomes were prepared for immunocytochemistry as described previously (De Camilli et al., 1983b), with minor modifications. To retain closed presynaptic terminals, synaptosomes were fixed for $10 \mathrm{~min}$ in an ice bath in isotonic conditions in $4 \%$ paraformaldehyde, $0.1 \%$ glutaraldehyde, 20 mm sodium cacodylate, $\mathrm{pH} 7.4,50 \mu \mathrm{M} \mathrm{CaCl}_{2}$, and $0.32 \mathrm{M}$ sucrose. To lyse the presynaptic terminals exposing the inner surface of the presynaptic membrane, synaptosomes were fixed for $10 \mathrm{~min}$ in the same solution but without $0.32 \mathrm{M}$ sucrose. The fixed synaptosomes were pelleted by centrifugation, resuspended in a small volume of $5 \mathrm{~mm}$ sodium cacodylate 

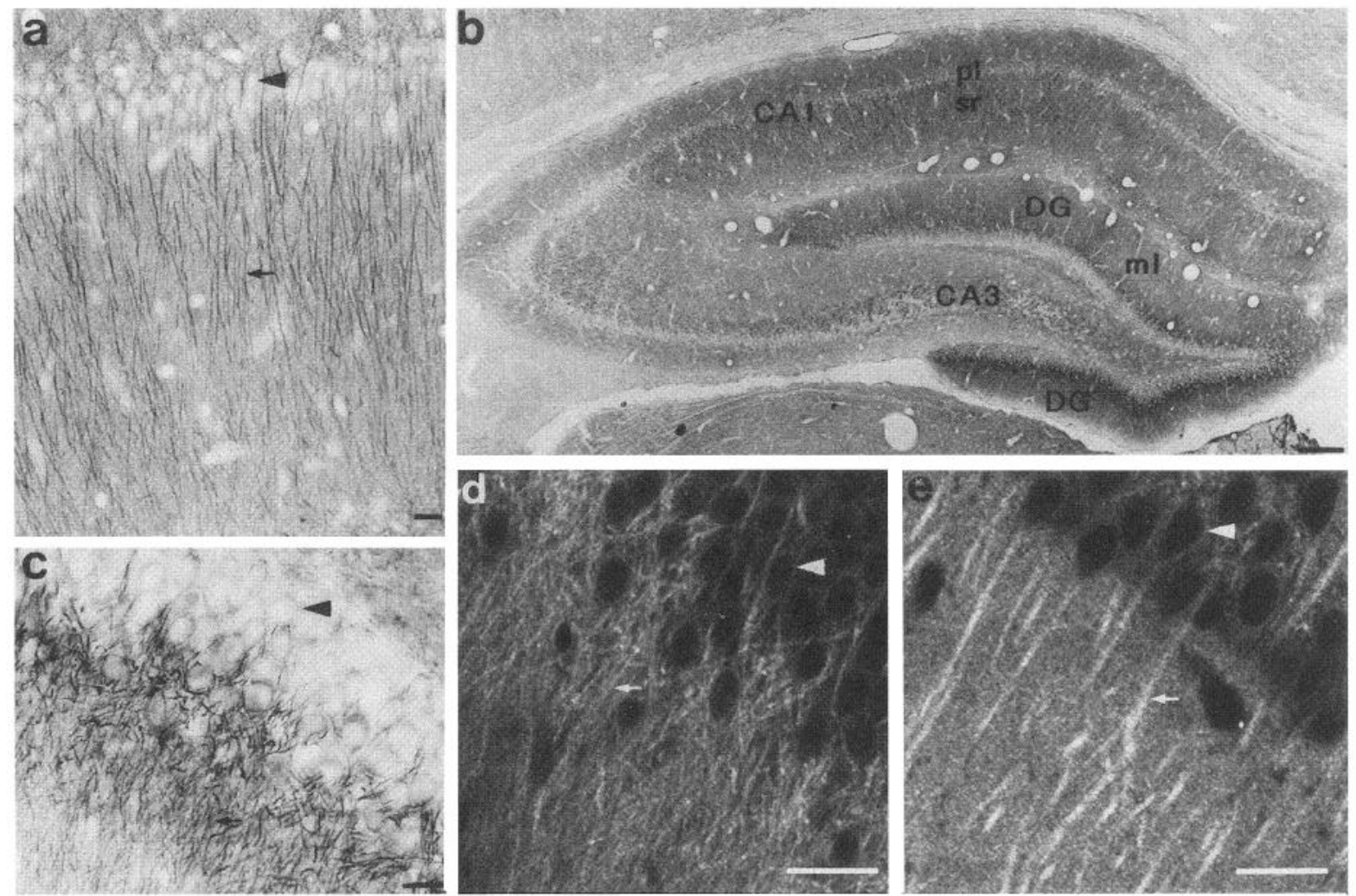

Figure 2. Immunocytochemical localization of PSD-95 in the rat hippocampus. PSD-95 was visualized in sections of hippocampus by HRP immunocytochemistry $(a-c)$ or by fluorescence immunocytochemistry in the confocal microscope $(d, e)$. All regions of the hippocampus are labeled $(b)$. Labeling is particularly dense, however, in dendrites of granule cells in the molecular layer of the dentate gyrus $(c, d)$ and in dendrites of pyramidal neurons in stratum radiatum of area CA1 $(a, e) . a, e$, High-magnification views of pyramidal cell somas (arrowheads) and labeled dendrites (arrows) in stratum radiatum of area CA1. $b$, Low-magnification view of labeled hippocampus ( $D G$, dentate gyrus; $m l$, molecular layer of the dentate gyrus; $C A 1$, area CA1; $p l$, pyramidal cell layer of area CA1; $s r$, stratum radiatum of area CA1; CA3, area CA3). $c, d$, High-magnification views of granule cell somas (arrowheads) and dendrites (arrows) in the molecular layer of the dentate gyrus. Scale bars: $a, c-e, 25 \mu \mathrm{m} ; b, 250 \mu \mathrm{m}$.
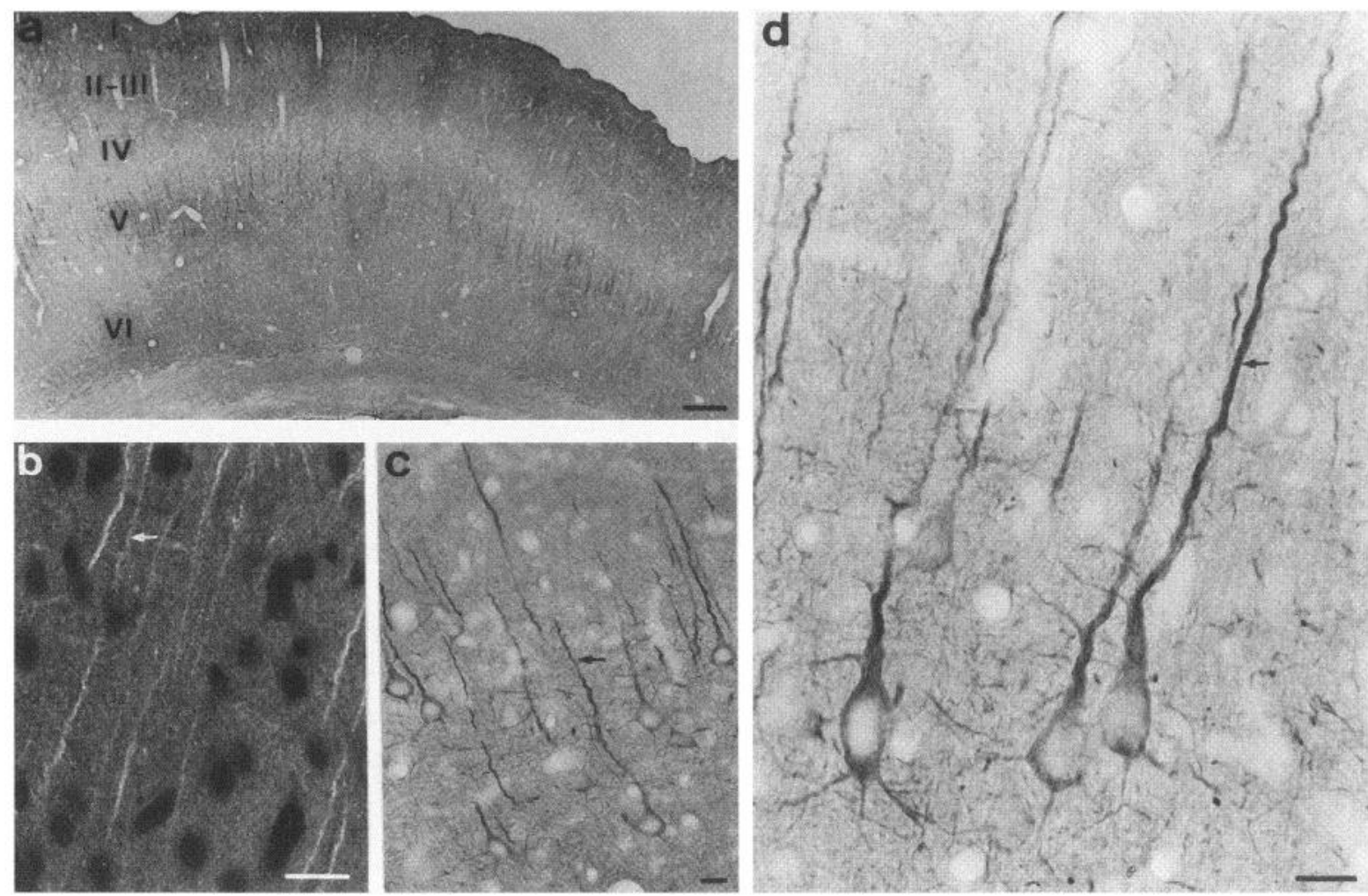

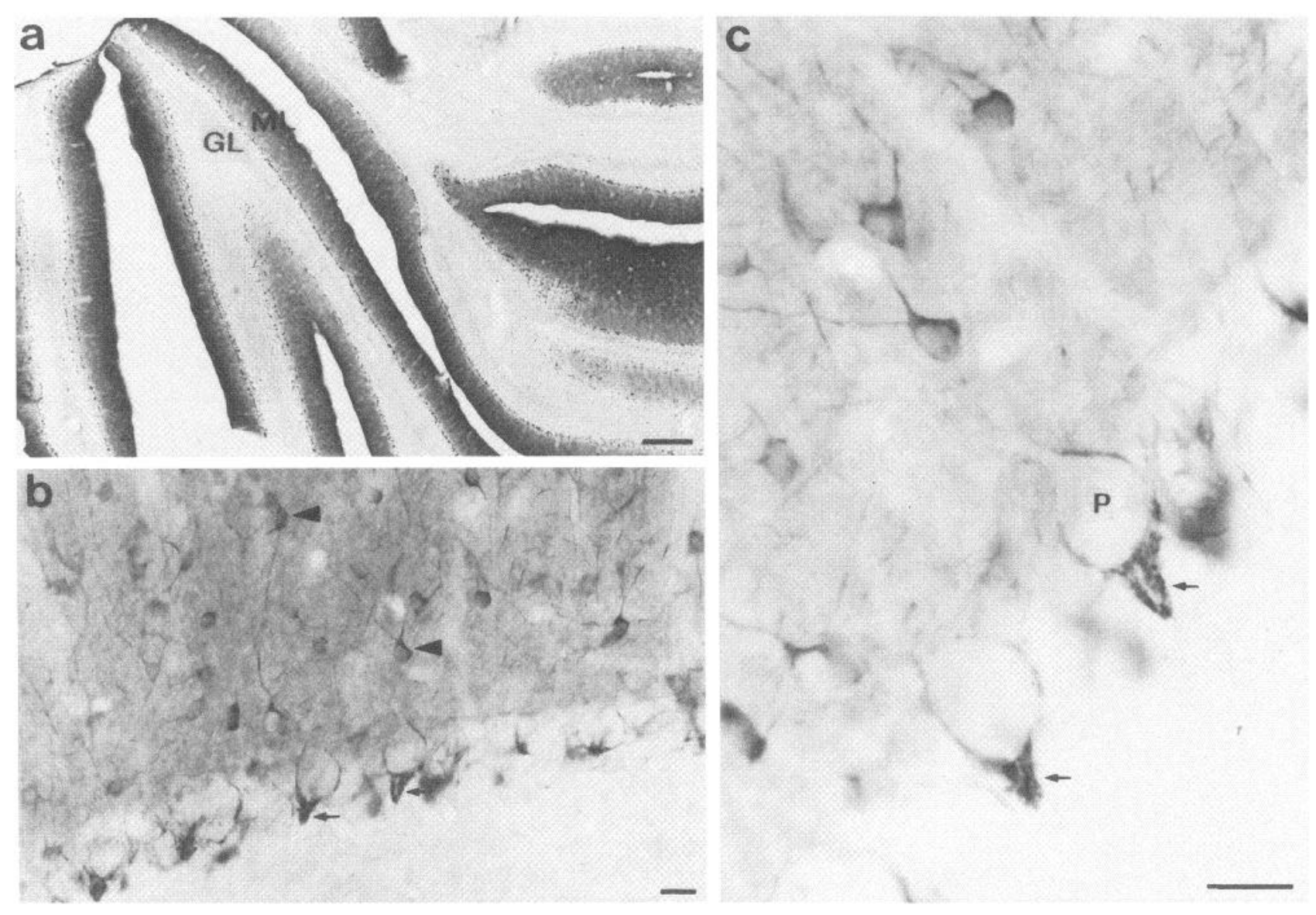

Figure 4. Immunocytochemical localization of PSD-95 in the rat cerebellum. PSD-95 was visualized in sections of cerebellum by HRP immunocytochemistry $(a-c)$. Purkinje cells $(P)$ and neurons in the granule layer $(G L)$ are not stained. The dendrites and somal cytoplasm of basket and stellate cells (arrowheads) in the molecular layer $(M L)$ are stained. The most intense immunoreactivity is evident in puncta within the basket cell terminal pinceau (arrows in $b$ and $c$ ). $a$, Low-magnification picture of staining in cerebellum. $b$, Higher magnification of staining at the border of the molecular and granule layers (arrowheads, basket and stellate cells; arrows, terminal pinceau of the basket cells). $c$, Higher magnification of two of the basket cell terminals pictured in $b$ ( $P$, Purkinje cell; arrows, terminal pinceau of the basket cells). Scale bars: $a, 500 \mu \mathrm{m} ; b, c, 25 \mu \mathrm{m}$.

buffer, $\mathrm{pH} 7.4$, and mixed with an equal volume of $3 \%$ low melting point agarose. The mixture was poured into a mold to form a thin slab and cut into $1 \mathrm{~mm}$ square blocks. Primary antibodies, diluted in solution $\mathrm{A}(0.5 \mathrm{M}$ $\mathrm{NaCl}, 100 \mathrm{mg} / \mathrm{ml}$ ovalbumin, $1.4 \mathrm{mg} / \mathrm{ml}$ goat $\mathrm{IgG}$, and $20 \mathrm{~mm}$ sodium phosphate, $\mathrm{pH} 7.4$ ), were incubated with the agarose blocks overnight at $4^{\circ} \mathrm{C}$. Affinity purified anti-PSD-95 antiserum was used at $15-100 \mu \mathrm{g} / \mathrm{ml}$. In one set of control incubations, an equivalent concentration of nonimmune rabbit IgG was used as the primary antibody; in another, the anti-PSD-95 antibodies were preabsorbed with a 2.5 -fold molar excess of recombinant PSD-95. An anti-synapsin antisera at 1:200 dilution was used as a positive control to establish that antibodies could diffuse into presynaptic terminals in the lysed synaptosome preparations. After five washes in solution $\mathrm{B}(0.5 \mathrm{M} \mathrm{NaCl}$ and $20 \mathrm{~mm}$ sodium phosphate, $\mathrm{pH} 7.4)$, the blocks were incubated for $2 \mathrm{hr}$ at room temperature in a 1:5 dilution of $10 \mathrm{nM}$ colloidal gold-conjugated goat anti-rabbit IgG in solution $\mathrm{A}$. The blocks were washed five times in solution $\mathrm{B}$ and then fixed in $1 \%$ glutaraldehyde and $0.12 \mathrm{M} \mathrm{NaP0}_{4}, \mathrm{pH} \mathrm{7.4,} \mathrm{osmicated} \mathrm{by} \mathrm{incubation} \mathrm{in} 1 \%$ osmium tetroxide, stained en bloc with $2 \%$ uranyl acetate, dehydrated, and embedded in Spurr's embedding medium according to the manufac- turer's instructions. Thin sections were cut on a Reichardt ultramicrotome and collected on Formvar-coated grids. The sections were contrasted by exposure to $2 \%$ uranyl acetate and $0.3 \%$ lead citrate and photographed in a Phillips EM 201 transmission electron microscope.

Immunogold quantification. Sections were observed systematically from the top left-hand corner to the bottom right-hand corner. All recognizable PSDs that were not enclosed by membrane structures that would have rendered them inaccessible to antibodies were photographed. Structures were classified as PSDs if (1) the typical dense thickening on the cytoplasmic face of the postsynaptic membrane was present, and (2) synaptic vesicles were assembled in the cytoplasm of the presynaptic terminal directly opposite the PSD. In sections stained with anti-synapsin antibodies, all lysed presynaptic terminals were photographed and analyzed. Fields were photographed at a magnification of 20,600 and printed at a final magnification of $\sim 145,000(1 \mathrm{~cm}=0.069 \mu \mathrm{m})$. A digitizer tablet and Sigma Scan software were used to count gold particles and to measure the lengths of PSDs in photographic prints. Data were tabulated and analyzed using Microsoft Excel.

Figure 3. Immunocytochemical localization of PSD-95 in the rat neocortex. PSD-95 was visualized in sections of neocortex by HRP immunocytochemistry $(a, c, d)$ or by fluorescence immunocytochemistry in the confocal microscope $(b)$. Immunoreactivity of individual neurons is more variable than in the hippocampus (a). Staining is most intense in laminae I and V, moderate in layers II-III and VI, and sparse in layer IV. Even in layer V, not all neurons are immunoreactive. Within layer $\mathrm{V}$ pyramidal cells, $(b-d)$, staining is most intense in the apical dendrites (arrows). Scale bars: $a, 250 \mu \mathrm{m} ; b-d, 25 \mu \mathrm{m}$. 

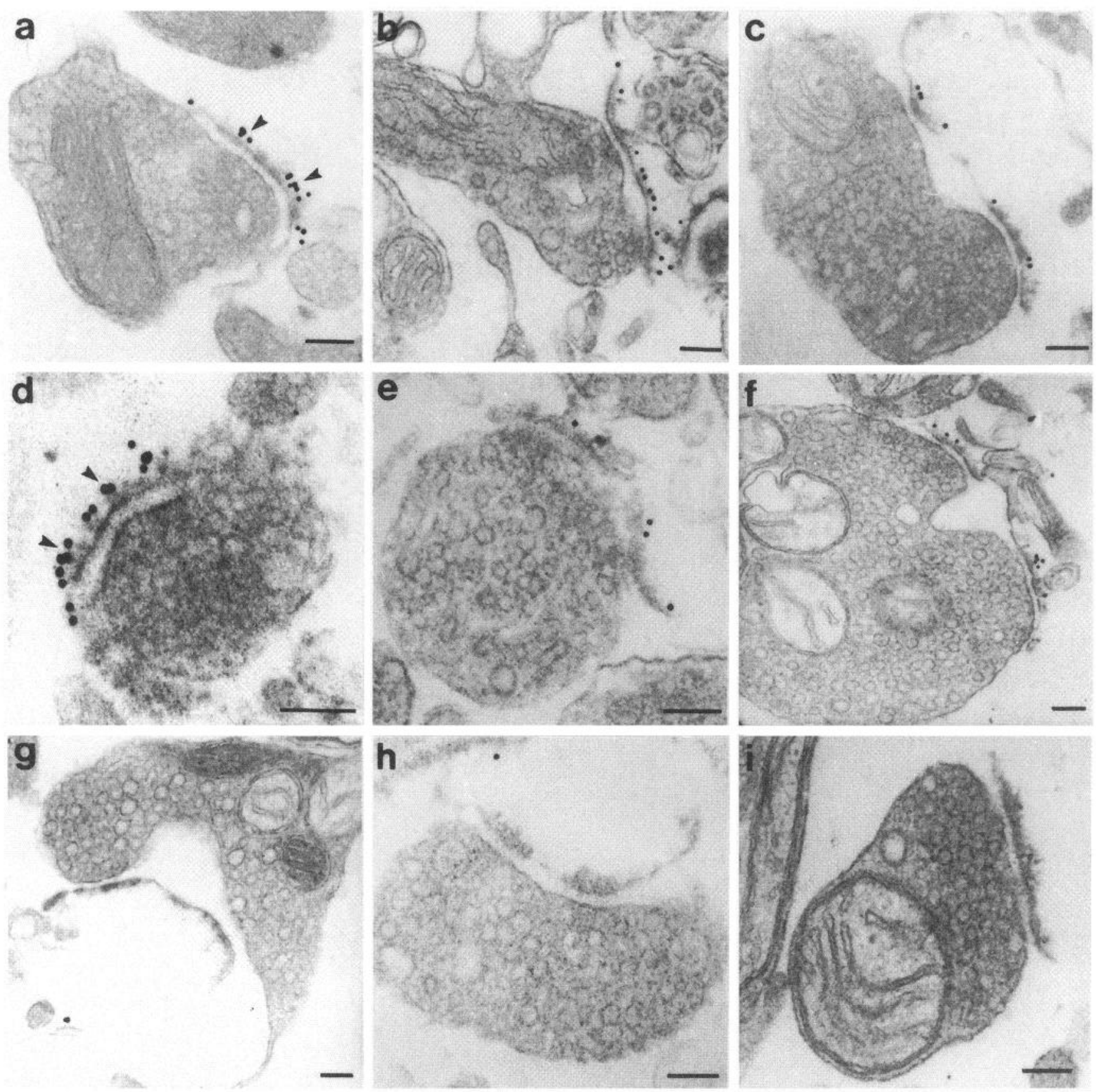

Figure 5. Immunocytochemical localization of PSD-95 in intact synaptosomes. PSD-95 was visualized in synaptosomes by EM after labeling with secondary antibodies conjugated to $10 \mathrm{~nm}$ gold particles. Synaptosomes were prepared in isotonic sucrose to preserve the structure of the presynaptic terminals. Gold particles are seen along the postsynaptic densities (arrowheads in $a$ and $d$ ) of synaptosomes that had been incubated with affinity-purified anti-PSD-95 antiserum ( $a-f)$. Only occasional gold particles (see Fig. 6) were associated with the postsynaptic densities of synaptosomes incubated with control antibodies $(g-i)$. Scale bars, $100 \mathrm{~nm}$.

\section{RESULTS}

\section{Specificity of antibodies to PSD-95}

Antiserum against recombinant PSD-95 was raised in rabbits as described in Materials and Methods. For the experiments shown here, antibodies to PSD-95 were affinity-purified on an Affigel column substituted with the recombinant protein (Cho et al., 1992). Because several homologs of PSD-95 have been described in the mammalian forebrain, we prepared immunoblots against homogenates of both forebrain and cerebellum, the latter being enriched in several PSD-95 homologs. In both cases, the antibod- ies react with the doublet of proteins at an apparent molecular weight of $\sim 95 \mathrm{kDa}$ that was identified as PSD-95 (Fig. 1) (Cho et al., 1992). All immunoreactivity is abolished by preabsorption of the sera with recombinant PSD-95 (Fig. 1). Notably, no reactive band was present at an apparent molecular weight of $140 \mathrm{kDa}$, the position on SDS gels of the closest homolog of PSD-95, SAP-97 (Muller et al., 1995). Slight reaction with protein bands at lower molecular weights is apparent. The lower molecular weight bands were present in similar amounts in several different rat brain homogenates, suggesting that they are not proteolytic products of 


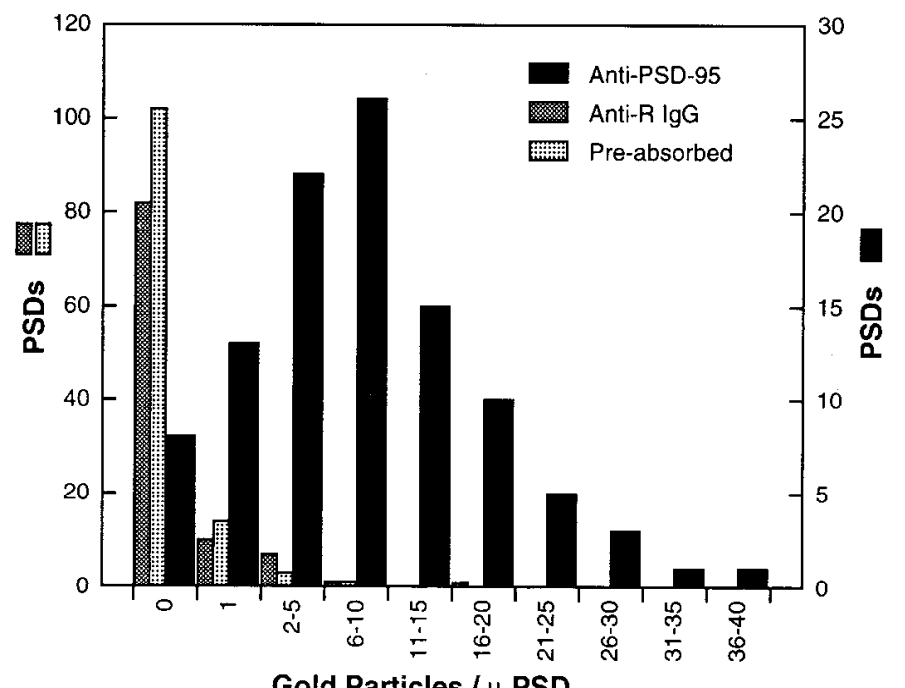

Figure 6. Distribution of gold particles associated with postsynaptic densities of intact synaptosomes. Data from sections examined in the experiments illustrated in Figure 5 were pooled and quantified as described in Materials and Methods; 104 synaptosomes labeled with Anti-PSD-95 antibodies (black bars), 101 labeled with nonimmune rabbit $\operatorname{IgG}$ (Anti-R IgG; gray bars), and 120 labeled with anti-PSD-95 antibodies that had been preabsorbed with recombinant PSD-95 (Pre-absorbed; dotted bars) were analyzed.

PSD-95 but may be alternatively spliced forms of the protein. The Drosophila homolog of PSD-95, the dlg protein, is extensively alternatively spliced (Woods and Bryant, 1991). When tissue sections were labeled with antibody to PSD-95, control sections were incubated with antisera preabsorbed with recombinant PSD95. Immunoreactivity was completely abolished by the preabsorption (data not shown).

\section{PSD-95 immunoreactivity is enriched in dendrites in several brain regions}

We first extended our earlier work (Cho et al., 1992) by determining the distribution of PSD-95 in neuronal domains throughout the brain by light microscopy. Immunoreactivity was detected by labeling either with a secondary antibody linked to immunoperoxidase or with a secondary antibody linked to a fluorescent dye followed by examination with a laser-scanning confocal fluorescence microscope. In the hippocampus, most dentate granule neurons are intensely stained (see also Cho et al., 1992), as are most pyramidal neurons in areas CA3 and CA1 (Fig. 2). Interneurons in the molecular layers do not appear to be stained. A population of pyramidal neurons in layers II-III and V-VI of the neocortex are stained (Fig. 3). Immunoreactivity is particularly intense in pyramidal neurons of layer $\mathrm{V}$ and is rare in granule neurons in layer IV.

In neurons in the hippocampus and neocortex, PSD-95 inmmnoreactivity is absent from cell nuclei and is considerably more intense in dendrites than in somata (Figs. $2 c-e, 3 b$ ). Although PSD-95 staining seems relatively uniform throughout individual dendrites and is clearly present within dendritic shafts, in confocal micrographs it often appears concentrated in small discrete spots (Fig. 2d,e), consistent with the possibility that PSD-95 is particularly highly concentrated at postsynaptic densities.

The staining pattern is quite different in the cerebellum. PSD-95 immunoreactivity is not present in Purkinje cell somata or dendrites but is visible in somata, dendrites, and axons of stellate cells in the molecular layer (Fig. 4). Furthermore, immunostaining is intense in an axonal plexus surrounding the axon hillock of each Purkinje cell that represents the unusual "pinceau" terminals of basket cells (Fig. 4c) (Palay and Chan-Palay, 1974; Hunt et al., 1992, and Kistner et al., 1993). This concentration of PSD-95 immunoreactivity in axon terminals is not observed in forebrain neurons.

Neurons in the striatum, amygdala, and septal nuclei are also immunoreactive for PSD-95, as are neurons in isolated nuclei in the midbrain and spinal cord (Hunt et al., 1992) (data not shown). 'The rather widespread distribution of this protein is consistent with the distribution of its message visualized by in situ hybridization (Kornau et al., 1995).

\section{PSD-95 is restricted to PSDs in forebrain synaptosomes}

To confirm that PSD-95 in fact is associated with the PSD in intact synaptosomes from thic forebrain and to determine whether it is also associated with the presynaptic membrane as might be predicted from the position of dlg in septate junctions and ZO-1 in tight junctions, we labeled synaptosomal PSD-95 with goldlabeled antibodies and localized it by EM. We used gold-labeled antibodies for the EM localization because the gold particles do not travel away from the carrier antibody as does electron-dense HRP reaclion product, which often precipitates nonspecifically on postsynaptic densities and mitochondrial membranes. We used synaptosomes for the EM study because in intact brain the postsynaptic spine often is not accessible to gold-labeled antibodies. In synaptosomes fixed under nonlytic conditions, the association of PSD-95 with the PSD is apparent (Figs. 5, 6). In these preparations, synaptosomal morphology is well preserved so that synaptosomes are identified readily, but the plasma membrane of the presynaptic terminal usually is closed so that antibodies would not be able to penetrate to the presynaptic facc of the synaptic junction. Therefore, we also examined synaptosomes fixed under lytic conditions. Synaptic junctions were identified by the presence of the PSD on one face of the membrane junction, with at least a few synaptic vesicles clinging to the opposite face. Labeled PSDs commonly were observed, but the presynaptic membrane was unlabeled (Figs. 7, 8). To confirm that antibodies were able to penetrate into lysed synaptosomes, a portion of the synaptosomes was incubated with anti-synapsin I antiserum, which labels presynaptic vesicles inside the terminal. Many terminals were labeled with the anti-synapsin antibodies (Fig. 9); hence, the absence of labeling of presynaptic membranes by the anti-PSD-95 antibody is not likely to be the result of poor penetration into the terminal.

The location of PSD-95 at the PSD in synaptosomes strengthens the conclusion that it associates with this structure in intact tissue. Moreover, the absence of labeling of the presynaptic membrane suggests that association of PSD-95 with synaptic junctions is asymmetric.

\section{DISCUSSION}

PSD-95 first was identified as a prominent component of the PSD fraction prepared from rat forebrain (Cho et al., 1992). Because this fraction is prepared by detergent extraction of forebrain synaptosomes (Cotman et al., 1974; Cohen et al., 1977), however, there is a possibility that certain proteins may become artifactually associated with it because of denaturation by the detergent. Therefore, association of a protein with the PSD fraction cannot be taken as proof of its association with the PSD in situ. Furthermore, PSD-95 has been localized in at 

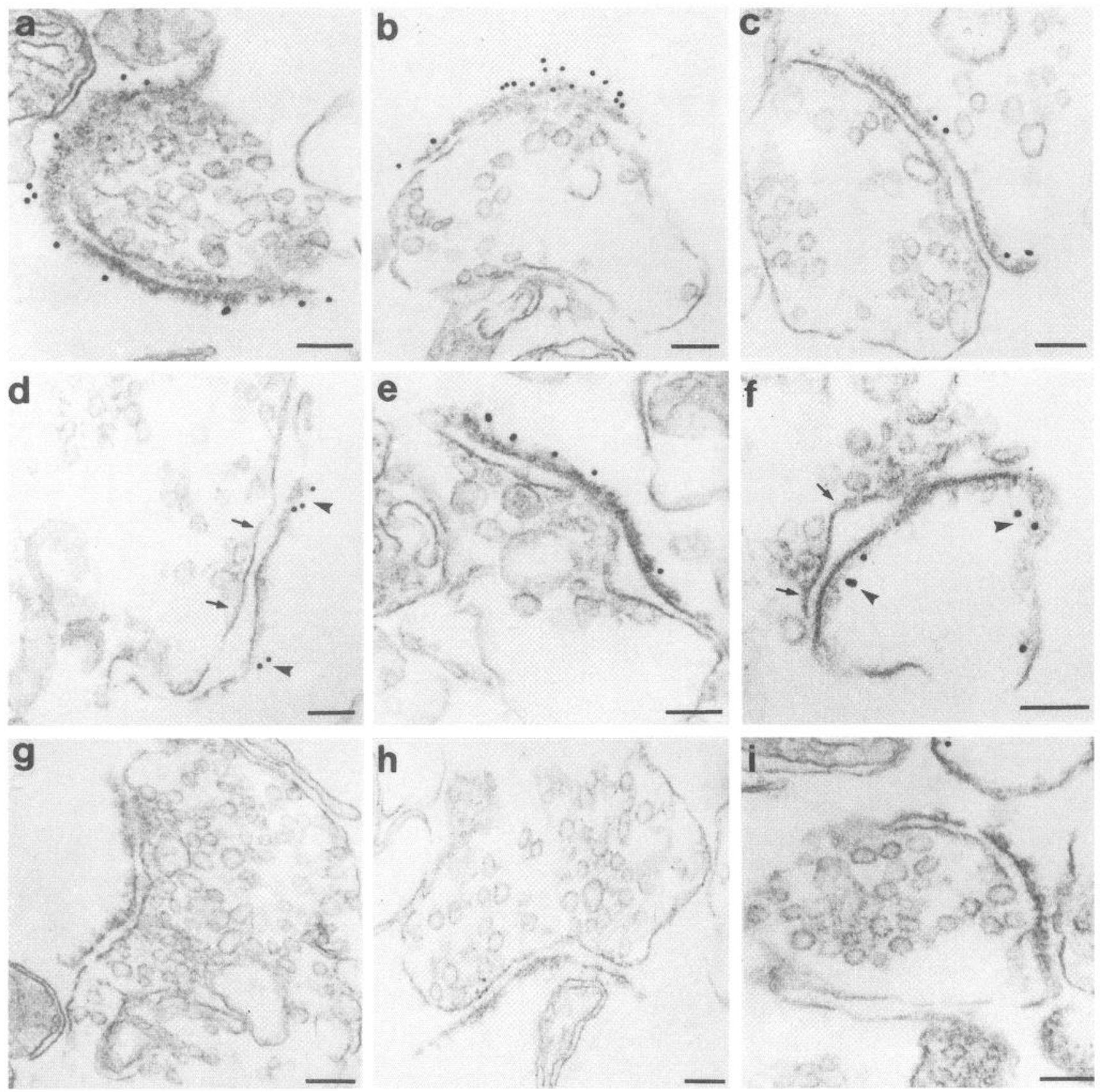

Figure 7. Immunocytochemical localization of PSD-95 in lysed synaptosomes. PSD-95 was visualized in synaptosomes by EM after labeling with secondary antibodies conjugated to $10 \mathrm{~nm}$ gold particles. Synaptosomes were prepared in low osmotic strength buffer to break the presynaptic terminals so that the inner face of the presynaptic membrane would be accessible to antibodies. Gold particles are seen along the postsynaptic densities (arrowheads in $d$ and $f$ ) of synaptosomes that had been incubated with affinity-purified anti-PSD-95 antiserum ( $a-f)$. No gold particles are associated with the presynaptic membranes (arrows in $d$ and $f$ ). Only occasional gold particles (see Fig. 8) were associated with the postsynaptic densities of synaptosomes incubated with control antibodies $(g-i)$. Scale bars, $100 \mathrm{~nm}$.

least one presynaptic terminal in the cerebellum by immunoperoxidase EM (Kistner et al., 1993). To circumvent the effects of detergents and determine more reliably the subcellular location of PSD-95 at forebrain synapses, we used immunogold EM to determine the location of PSD-95 in forebrain synaptosomes before detergent extraction. Immunogold labeling is more reliable than immunoperoxidase labeling at the level of the electron microscope because the peroxidase reaction product often is deposited artifactually on nearby cellular structures that do not contain the antigen of interest. The results support our original hypothesis that PSD-95 is a component of PSDs (Figs. 5-8). Furthermore, we could not detect any association of PSD-95 with the presynaptic face of the synaptic junction (Figs. 7, 8). Thus, in contrast to dlg and ZO-1, PSD-95 is distributed asymmetrically at forebrain synaptic junctions, associating principally with the postsynaptic side. Thus, any functional role of PSD-95 would be exercised disproportionately on the postsynaptic side of the junction, most likely in association with NMDA-type glutamate receptors (Kornau et al., 1995). It remains possible, however, that PSD-95 is present in forebrain 


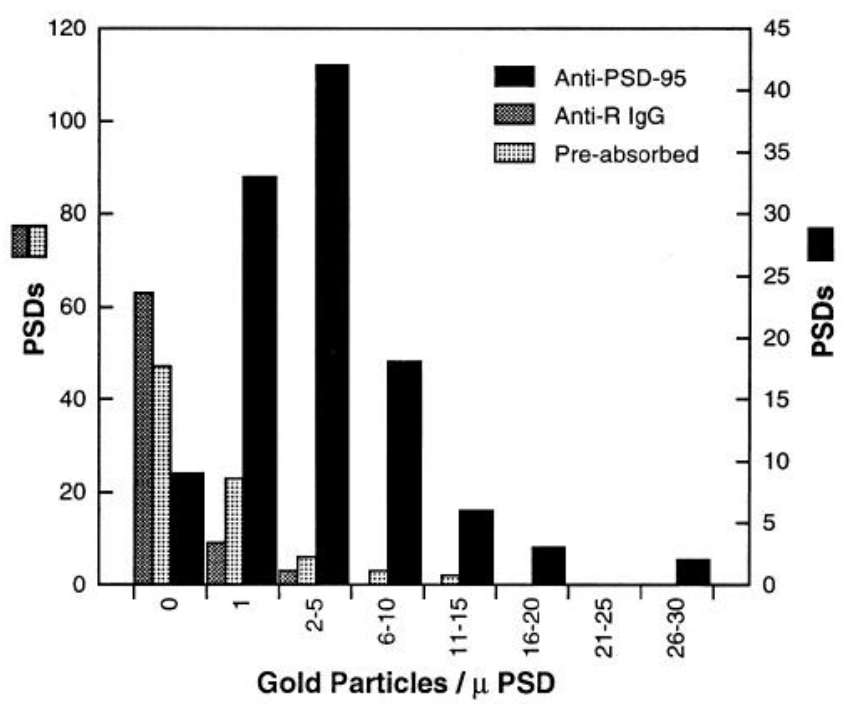

Figure 8. Distribution of gold particles associated with postsynaptic densities of lysed synaptosomes. Data from sections examined in the experiments illustrated in Figure 7 were pooled and quantified as described in Materials and Methods; 113 synaptosomes labeled with Anti-PSD-95 antibodies (black bars), 75 labeled with nonimmune rabbit $\operatorname{IgG}$ (Anti- $R \lg G$; gray bars), and 81 labeled with anti-PSD-95 antibodies that had been preabsorbed with recombinant PSD-95 (Pre-absorbed; dotted bars) were analyzed.

presynaptic terminals in a soluble form, or that it associates with other membrane proteins in different parts of the neuron. Indeed, all other identified proteins in the PSD fraction that are not transmembrane proteins are partially soluble in brain homogenates and are not located exclusively in the PSD (Kennedy, 1993).

The high expression of PSD-95 in the presynaptic plexus of cerebellar basket cells reported here (Fig. 4) and by Kistner et al. (1993) and its absence in the postsynaptic Purkinje neurons are apparently not representative of its distribution at most synapses. In the cerebellum, the relatively rare stellate and basket cells are the only neurons stained (Fig. 4). The presynaptic terminals of the basket cells are strongly immunoreactive (Fig. 4c) (Kistner et al., 1993), as are their somata and den- drites (Fig. 4b). In contrast, in the forebrain PSD-95 is expressed in a majority of neurons (Figs. 2, 3) and is considerably more concentrated in dendrites than in somata, axons, or presynaptic terminals (Figs. 2, 3) (Cho et al., 1992). The explanation for the aberrant high expression of PSD-95 in the basket cell terminal plexus may lie in its unusual morphology, which is unique in the mammalian brain (Palay and ChanPalay, 1974). Converging axons of several basket cells form a "basket" around the soma of each Purkinje cell (hence their name) and then descend and branch into a dense plexus termed a "pinceau" that surrounds the base of the axon between the soma and the beginning of the myelin sheath (see Fig. 4c). Each large pinceau makes only a few chemical synapses onto the Purkinje axon at a position about one third of the way from the Purkinje soma to the myelin sheath. The axon is otherwise shielded from the pinceau by a neuroglial sheath. The highly branched axons in the pinceau are filled with synaptic vesicles, but the function of most of these vesicles is not known because they are not located near a synaptic junction. The dense clusters of peroxidase reaction product throughout the pinceau of the basket cell (Fig. 4c) clearly are not associated with the few synaptic junctions located near the axon. Similarly, the HRP reaction product visualized by Kistner et al. (1993) was present throughout the presynaptic plexus and was not located exclusively near synaptic junctions. Several morphologists have made the interesting observation that the converging presynaptic processes within the pinceau are bound together by intermembrane junctions with a morphology similar to that of septate junctions in insects (Gobel, 1971; Sotelo and Llinas, 1972; Palay and Chan-Palay, 1974). Such junctions are not found elsewhere in the mammalian nervous system. Thus, the presence of PSD-95 immunoreactivity within the basket cell terminal plexus may be related to the presence of these unusual septate junctions.

PSD-95, dlg, and ZO-1 are cytosolic proteins that associate with intercellular junctions through their interaction with the submembrane cytoskeleton. The conserved domains within the three proteins provide clues about their possible common functions. Each of the proteins contains a src-homology 3 (SH3) domain, a domain of high homology with yeast and pig guanylate kinases (Woods
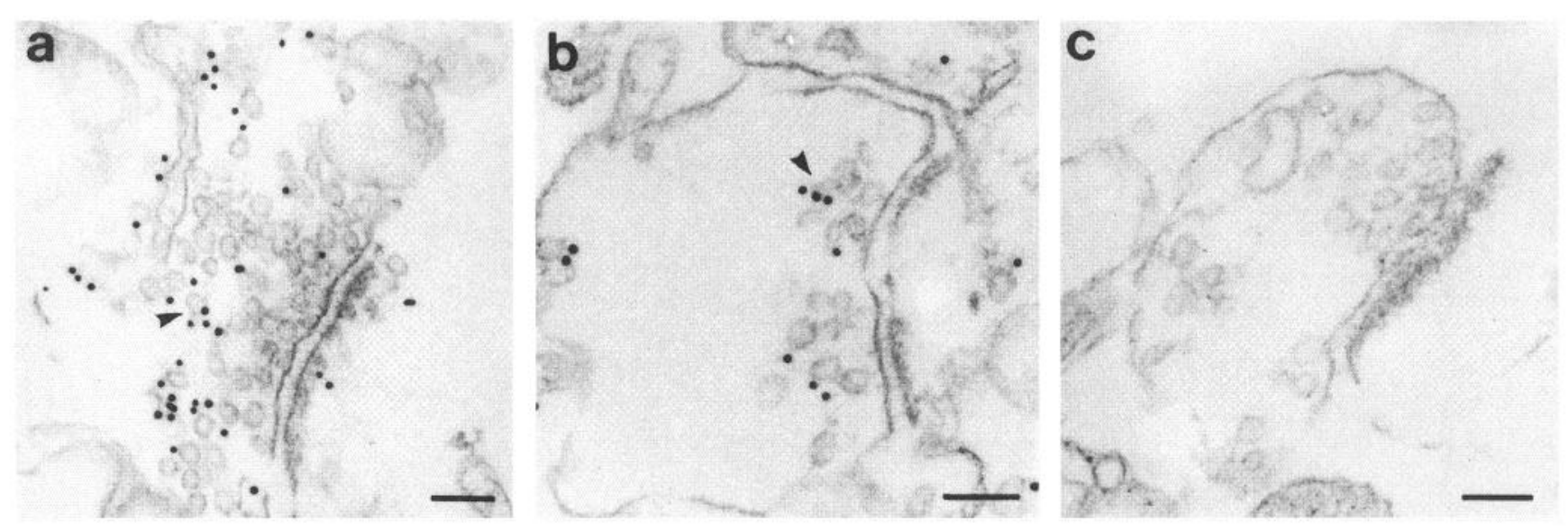

Figure 9. Immunocytochemical localization of synapsin I in lysed synaptosomes. Synapsin was visualized in synaptosomes by EM after labeling with secondary antibodies conjugated to $10 \mathrm{~nm}$ gold particles. Synaptosomes were prepared as in Figure 7. Gold particles are associated with synaptic vesicles (arrowheads) inside the presynaptic terminals of synaptosomes that had been incubated with anti-synapsin antiserum $(a, b)$. Occasional gold particles are associated with postsynaptic densities, as also reported by DeCamilli et al. (1983). Very few gold particles were found in synaptosomes incubated with control antibodies $(c)$. Scale bars, $100 \mathrm{~nm}$. 
and Bryant, 1991; Cho et al., 1992; Willott et al., 1993), and a set of three 90-amino-acid PDZ repeats (PSD-95, Discs-large, ZO-1; previously termed "GLGF" repeats; Cho et al., 1992). The second PDZ domain binds to a C-tenninal motif, $\mathrm{tSXV}$, which is present in NMDA-receptor subunits (Kornau et al., 1995). The role of PDZ 1 and 3 is not yet known. The PDZ motif has been found in a rapidly growing list of molecules believed to participate in signaling at intercellular junctions, including cerebellar nitric oxide synthase (Bredt et al., 1991), the protein product of the Drosophila segment polarity gene dishevelled (Klingensmith et al., 1994), and a protein tyrosine phosphatase (Maekawa et al., 1994). The third PDZ domain of the tyrosine phosphatase interacts with a tSXV domain in the Fas receptor that controls apoptosis in several cell types (Sato et al., 1995). Thus, the PDZ motif may represent a modular protein-binding domain that holds proteins together at defined points in the cell membrane. SH3 domains generally mediate associations with various signal transduction molecules, many of which regulate ras-related small GTP-binding proteins (Pawson and Gish, 1992), suggesting that PSD-95, dlg, and ZO-1 may participate in GTP-regulated signal transduction. Another indication that the three proteins may perform a function involving guanine nucleotide binding is that their guanylate kinase domains are disrupted at a critical portion of the ATP-binding site. Thus, it has been postulated that the guanylate kinase domains may bind nucleotides but not synthesize GDP (Koonin et al., 1992; Willott et al., 1993; Kistner et al., 1995).

Although PSD-95 may have various binding and signaling functions in different parts of neurons, our results demonstrate that at forebrain synapses it functions predominantly, if not exclusively, on the postsynaptic side.

\section{REFERENCES}

Adams JC (1981) Heavy metal intensification of DAB-based HRP reaction product. J IIistochem Cytochem 29:775.

Banker G, Churchill L, Cotman CW (1974) Proteins of the postsynaptic density. J Cell Biol 63:456-465.

Bredt DS, Hwang PM, Glatt CE, Lowenstein C, Reed RR, Snyder SH (1991) Cloned and expressed nitric oxide synthase structurally resembles cytochrome P-450 reductase. Nature 351:714 -718.

Carlin RK, Grab DJ, Cohen RS, Siekevitz P (1980) Isolation and characterization of postsynaptic densities from various brain regions: enrichment of different types of postsynaptic densities. J Cell Biol 86:831-843.

Carlin RK, Bartelt D, Siekevitz P (1983) Identification of fodrin as a major calmodulin-binding protein in postsynaptic density preparations. J Cell Biol 96:443-448.

Cho K-O, Hunt CA, Kennedy MB (1992) The rat brain postsynaptic density fraction contains a homolog of the Drosophila discs-large tumor suppressor protein. Neuron 9:929-942.

Citi S (1993) The molecular organization of tight junctions. J Cell Biol 121:485-489.

Cohen RS, Blomberg F, Berzins K, Siekevitz P (1977) The structure of postsynaptic densities isolated from dog cerebral cortex. I. Overall morphology and protein composition. J Cell Biol 74:181-203.

Colonnier M (1968) Synaptic patterns on different cell types in the different laminae of the cat visual cortex: an electron microscope study. Brain Res 9:268-287.

Cotman CW, Banker B, Churchill L, Taylor D (1974) Isolation of postsynaptic densities from rat brain. J Cell Biol 63:441-455.

De Camilli P, Cameron R, Greengard P (1983a) Synapsin I (Protein I), a nerve terminal-specific phosphoprotein. I. Its general distribution in synapses of the central and peripheral nervous system demonstrated by immunofluorescence in frozen and plastic sections. J Cell Biol 96:1337-1354.

De Camilli P, Harris Jr SM, Huttner WB, Greengard P (1983b) Synapsin I (Protein I), a nerve terminal-specific phosphoprotein. II. Its specific association with synaptic vesicles demonstrated by immunocytochemistry in agarose-embedded synaptosomes. J Cell Biol 96:1355-1373.

Gobel S (1971) Axo-axonic septate junctions in the basket formations of the cat cerebellar cortex. J Cell Biol 51:328-333.
Gray EG (1959) Axo-somatic and axo-dendritic synapses of the cerebral cortex: an electron microscope study. J Anat 93:420-433.

Hunt CA, Cho K-O, Kennedy MB (1992) Distribution of the postsynaptic density protein, PSD-95, in rat brain. Soc Neurosci Abstr 18:1336.

Itoh M, Nagafuchi A, Yonemura S, Kitani-Yasuda T, Tsukita S, Tsukita S (1993) The 220-kd protein colocalizing with cadherins in non-epithelial cells is identical to ZO-1, a tight junction-associated protein in epithelial cells: cDNA cloning and immunoelectron microscopy. J Cell Biol 121:491-502.

Kelly PT, Cotman CW (1978) Synaptic proteins. Characterization of tubulin and actin and identification of a distinct postsynaptic density polypeptide. J Cell Biol 79:173-183.

Kelly PT, McGuinness TL, Greengard P (1984) Evidence that the major postsynaptic density protein is a component of a $\mathrm{Ca}^{2+} /$ calmodulindependent protein kinase. Proc Natl Acad Sci USA 81:945-949.

Kennedy MB (1993) The postsynaptic density. Curr Opin Neurobiol 3:732-737.

Kennedy MB, Bennett MK, Erondu NE (1983) Biochemical and immunochemical evidence that the "major postsynaptic density protein" is a subunit of a calmodulin-dependent protein kinase. Proc Natl Acad Sci USA 80:7357-7361.

Kennedy MB, Bennett MK, Bulleit RF, Erondu NE, Jennings VR, Miller SM, Moiloy SS, Patton BL, Schenker LJ (1990) Structure and regulation of type II calcium/calmodulin-dependent protein kinase in central nervous system neurons. Cold Spring Harb Symp Quant Biol 55:101-110.

Kim E, Neithammer M, Rothschild A, Jan Y-N, Sheng M (1995) Clustering of Shaker type $\mathrm{K}^{+}$channels by interaction with a family of membrane-associated guanylyl kinases. Nature 378:85-88.

Kistner U, Wenzel BM, Veh RW, Cases-Langhoff C, Garner AM, Appeltauer U, Vuss B, Gundelfinger ED, Gamer CC (1993) SAP90, a rat presynaptic protein related to the product of the Drosophila tumor suppressor gene dlg-A. J Biol Chem 268:4580-4583.

Kistner U, Garner CC, Linial M (1995) Nucleotide-binding by the synapse associated protein sap90. FEBS Lett 359:159-163.

Klingensmith J, Nusse R, Perrimon N (1994) The Drosophila segment polarity gene dishevelled encodes a novel protein required for response to the wingless signal. Genes Dev 8:118-130.

Koonin EV, Woods DF, Bryant PJ (1992) Dlg-R proteins: modified guanylate kinases. Nature Genet 2:256-257.

Kornau H-C, Schenker LT, Kennedy MB, Seeburg PH (1995) Domain interaction between NMDA receptor subunits and the postsynaptic density protein PSD-95. Science 269:1737-1740.

Landis DMD, Reese TS, Raviola S (1974) Differences in membrane structure between excitatory and inhibilory components of the reciprocal synapse in the olfactory bulb. J Comp Neurol 155:67-92.

Maekawa K, Imagawa N, Nagamatsu M, Harada S (1994) Molecular cloning of a novel protein-tyrosine phosphatase containing a membranebinding domain and GLGF repeats. FEBS Lett 337:200-206.

Muller BM, Kistner U, Veh RW, Caseslanghoff C, Becker B, Gundelfinger ED, Garner CC (1995) Molecular characterization and spatialdistribution of sap97, a novel presynaptic protein homologous to sap90 and the Drosophila disks-large tumor-suppressor protein. J Neurosci $15: 2354-2366$.

Noirot-Timothee C, Noirot C (1980) Septate and scalariform junctions in arthropods. Int Rev Cytol 63:97 140.

Palay SL (1956) Synapses in the central nervous system. J Biophys Biochem Cytol 2:193-202.

Palay SL, Chan-Palay V (1974) The basket cell. In: Cerebellar cortex, pp 180-216. New York: Springer.

Pawson T, Gish GD (1992) SH2 and SH3 domains: from structure to function. Cell 71:359-362.

Sato T, Irie S, Kitada S, Reed JC (1995) FAP-1: a protein-tyrosinephosphatase that associates with Fas. Science 268:411-415.

Sotelo C, Llinas R (1972) Specialized membrane junctions between neurons in the vertebrate cerebellar cortex. J Cell Biol 53:271-289.

Willott E, Balda MS, Heintzelman M, Jameson B, Anderson JM (1992) Localization and differential expression of two isoforms of the tight junction protein ZO-1. Am J Physiol 262:C1119-C1124.

Willott W, Balda MS, Fanning $\Lambda \mathrm{S}$, Jameson B, Van Itallie C, Anderson JM (1993) The tight junction protein ZO-1 is homologous to the Drosophila discs-large tumor suppressor protein of septate junctions. Proc Natl Acad Sci USA 90:7834-7838.

Woods DF, Bryant PJ (1991) The discs-large tumor suppressor gene of Drosophila encodes a guanylate kinase homolog localized at septate junctions. Cell 66:451-464. 